\title{
A Study of Impressions of One Minor Music
}

\author{
Satoshi Watanabe* ${ }^{* \dagger}$ Member, Naruki Shirahama ${ }^{*}$ Member \\ NAOFumi NAKAYA ${ }^{\S} \quad$ Member, Yuji Matsumoto ${ }^{\mathbb{I}} \quad$ Non-member
}

(Received September 30, 2021, revised October 20, 2021)

\begin{abstract}
This paper describes the study of impressions of Minor music. The experiment employed two groups of healthy people (one group has eight people and the other one has twenty-two) and one Minor music ("Requiem (Mozart)") as participants and test piece, respectively. The experiment data are collected using Visual Analog Scale (VAS) measure and analyzed using box-and-whisker plot, univariate scatter plot and cluster analysis. All participants listen to the Minor music individually. To investigate their impression of the Minor music, they answer the questionnaire on VAS (7 questions: "Bright-Dark", "Happy-Sad", and so on) individually. The results obtained from the two groups of participants are similar; they show that subjective evaluation values based on the impression of the Minor music ("Sad", "Dark", and so on) have been obtained and visualized by the combination of box-and-whisker plot and univariate scatter plot. The study result shows that the questions based on similar impressions belong to the same cluster.
\end{abstract}

Keywords: Visual analog scale, Impression of one Minor music, Participants, Small samples, Box-and-whisker Plot, Univariate scatter plot.

\section{Introduction}

The purpose of this paper is the expression and comparison of the experimental results for the impressions of Minor music using box-and-whisker plot, univariate scatter plot and cluster analysis based on Visual Analog Scale (VAS) by two groups of participants. To clarify the impression of the Minor music, experiment participants are asked to listen to the Minor music, and they are also asked to answer the questionnaire about an impression of the Minor music by VAS.

To investigate under this condition, the authors focused on four points of elements; (1) Selection of the Minor music, (2) Reasons why VAS was adopted for a questionnaire about impression of the Minor music, (3) Analysis method that enables the feature extraction with small samples, and (4) Experiment participants. First of all, these backgrounds are explained below.

(1) Selection of the Minor music: The effects of music listening to improve quality of life (QOL) for humans have been, gradually, confirmed and accepted by many people [1]. However, factors of the effects of listening to music to improve QOL for humans are not clear. To solve this

\footnotetext{
* Corresponding: satoshi-w@iuhw.ac.jp

$\dagger$ School of Health Sciences at Odawara, International University of Health and Welfare

1-2-25, Shiroyama, Odawara-shi, Kanagawa, 250-8588, Japan

$\doteqdot$ Department of Creative Engineering, National Institute of Technology (KOSEN), Kitakyushu College

5-20-1, Shii, Kokuraminami-ku, Kitakyushu-shi, Fukuoka, 802-0985, Japan

$\S$ Faculty of Health Sciences,Tsukuba International University 6-20-1, Manabe, Tsuchiura-shi, Ibaraki, 300-0051, Japan

II Junior College Division, Kindai University

3-4-1, Kowakae, Higashiosaka-shi, Osaka, 577-8502, Japan
}

Question: How is your impression about this music?

\begin{tabular}{ccccccc} 
Bright & 1 & 2 & 3 & 4 & 5 & Dark \\
& \multicolumn{5}{c}{ (a) LS }
\end{tabular}

Question: How is your impression about this music?

Bright Dark

(b) VAS

Figure 1: Typical types of LS and VAS.

problem investigations about listening to various music are important. Under such background and our previous study [2], one Minor music ("Requiem (Mozart)") is prepared for this attempt.

(2) Reasons why VAS was adopted for a questionnaire about the impression of the Minor music: Recently, studies on the subjective evaluation (such as the impression of music) based on Likert Scale (LS, see Fig. 1a) [3] have been conducted broadly. LS is a simple discrete scale method, but it has some weak points such as halo effect, leniency effect, central tendency, and so on [4] [7]. From these points, it is suggested that there exists unintended bias on LS's results [8] [9]. In order to solve these weak points, VAS (see Fig. 1b) is investigated on the subjective evaluation [8] [9]. VAS is a ratio scale method, it is expected that it can solve the weak points of LS as mentioned above [8] [9]. Therefore, it is considered that VAS is more flexible than LS.

(3) Analysis method that enables the feature extraction with small samples: In general, it is necessary to employ a large number of measurements of subjective evaluation based on LS to obtain reliable conclusions. How- 
ever, as a human-centered computing field, it needs to give an accurate result by a small number of subjective evaluation measurements. To understand these data's distribution and other characteristics, Weissgerber et al.. propose that a combination of box-and-whisker plot and univariate scatter plot of them should be drawn [10]. Therefore, a new method of subjective evaluation using VAS [11] has been developed under their proposal [10]. That is, this method consists of three elements: (a) Questionnaire on VAS (2 pole item), (b) Visualization (combination of univariate scatter plot and box-and-whisker plot), and (c) Clustering (hierarchical clustering analysis by Ward method and non-hierarchical clustering analysis by k-means). And this method is called "Shirahama-Watanabe Method" (SWM). Furthermore, SWM has been applied to several studies [12] [13] and contributes to feature extraction from experimental results with small samples.

(4) Experiment participants: It shows that the difference of the impression by the different music or sound can be expressed using SWM [11] in the results of our previous study [2] [12]. On the other hand, this study focused on the comparison of experimental results due to different groups of participants (thus, eight people group and twenty-two people group are invited as the experiment participants in this attempt).

Under such conditions and our previous study [2] [12], in order to express and compare the experimental results, one Minor music ("Requiem (Mozart)") and the questionnaire on VAS are prepared for this attempt. Furthermore, two groups of healthy people (eight people group and twentytwo people group) are invited as the experiment participants. Moreover, SWM [11] is used in this attempt.

That is, this paper describes that the expression and comparison of the experimental results for the impression of one Minor music using a box-and-whisker plot, univariate scatter plot and cluster analysis.

The remainder of this paper is organized as follows. Section 2 describes the theory of VAS and its visualization analysis. Materials and methods are shown in Section 3. Results and discussion are given in Section 4. Section 5 shows the conclusions and future works.

\section{Theory of Impression of Music Based on VAS and its Visualization}

2.1 VAS In recent years, VAS has been applied to study subjective evaluation such as education [8] [9] [13], an impression of music [2] [12], impression received from the response of a communication robot [11], and so on. This paper first introduces VAS. Fig. 1b shows the typical types of VAS questionnaires. This is to ask the impression of the music. To answer Fig. 1b, the response is marked by drawing a vertical line on the horizontal line.

An example of the response to VAS questionnaire is shown in Fig. 2. And the calculation of VAS data is also shown in Fig. 2. VAS's results are determined by the ratio of (a) to (b) (in other words, it is determined by the position of the mark on the line). As mentioned above, a value of subjective evaluation, i.e., the value of the impression of

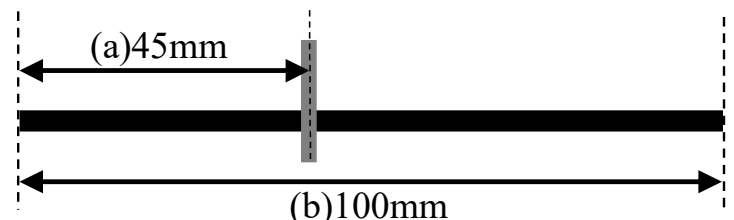

(b) $100 \mathrm{~mm}$

value of subjective evaluation $=(\mathrm{a}) /(\mathrm{b})=0.45($ or $45.0 \%)$

Figure 2: Example of calculation of VAS data.

the music (between 0.00 to 1.00) can be obtained.

2.2 The Method of Subjective Evaluation Using VAS for Small Sample Data Analysis (Shirahama WatanabeMethod, SWM) [11] This paper applies the method called SWM [11]. SWM has been developed for small sample data analysis based on VAS questionnaires. And SWM consists of three elements: (a) Questionnaire on VAS (2 pole item), (b) Visualization (combination of univariate scatter plot and box-and-whisker plot), and (c) Clustering (hierarchical clustering analysis by Ward method and non-hierarchical clustering analysis by k-means).

\subsection{Expression of Impression of Music Based on SWM}

[11] By the expression of values (impression of music) obtained in 2.2, it is possible to know their characteristics. To clarify their characteristics, the analysis is carried out by $\mathrm{R}$ environment. First, the basic statistics and correlation matrices are calculated, the outlines of distribution and relationships of values are obtained. Next, a combination of box-and-whisker plots and univariate scatter plots [10] is drawn, and this is our unique method [2] [11] [13] that is called SWM. Moreover, hierarchical clustering analysis by Ward method and non-hierarchical clustering analysis by k-means are carried out. Under these procedures, relationships and meanings of an impression of music can be understood [2] [11] [13].

\section{Materials and Methods}

\subsection{Expression of Impression of One Minor Music}

Based on SWM The Experiments consist of listening to a piece of Minor music and answering the questionnaire on VAS, these are conducted by the first group (G1) and the second group (G2) separately.

As the test piece, one Minor music ("Requiem (Mozart)") is employed (This music is selected in connection with our previous studies [2] [12]). All participants are asked to listen to the test piece individually. In order to analyze their impression of the Minor music, they are asked to answer the questionnaire [14] on VAS (see Fig. 3) individually. By the expression of values (impression of the Minor music) obtained in this procedure, it is possible to know their characteristics; the basic statistics and correlation matrices, visualization (combination of univariate scatter plot and box-andwhisker plot), and clustering (hierarchical clustering analysis by Ward method and non-hierarchical clustering analysis by k-means) [2] [11] [13]. 


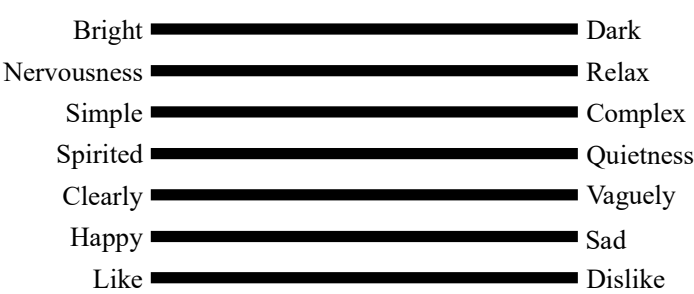

(These questionnaires are numbered from top to bottom (as Q1

(“Bright-Dark”), Q2(“Nervousness-Relax”), Q3 (“Simple-

Complex"), ..., Q7 (“Like-Dislike”)).)

Figure 3: Questionnaires relating to the impression of Minor music [14] for VAS.

3.2 Participants Two groups of healthy people are invited as the experiment participants; G1 consists of eight male people (all their ages are 21 years old), and G2 consists of twenty-two male and female people (male: 16 people, female: 6 people, ages: 21.04 \pm 3.54 years old (mean \pm standard deviation)). And it has been confirmed that all participants have no knowledge of the test piece.

Ethical considerations are as follows:

The explanation of this study is given orally, and the documents are distributed to the participants. And participation in this study is voluntary. Furthermore, the data has been collected anonymously and has been only used for the presentation of this study.

\section{Results and Discussion}

4.1 Basic Statistics and Correlation Matrices Table 1 shows the basic statistics of questionnaires relating to the impression of the Minor music based on VAS, from Q1 to Q7. In Table 1, the results of G1 and G2 are similar, it can be seen that the maximum value of the difference of standard deviation is 0.10 (see Table $1 b$ ). From these facts, it is considered that participants received similar impressions from the Minor music. On the other hand, the distribution of VAS data is relating to the impression of the Minor music; especially, trends of Table 1a (Bright (0.00)-Dark (1.00)), (e) (Clearly (0.00)-Vaguely (1.00)) and (f) (Happy (0.00)Sad (1.00)) are characteristic; it is found that the trends of the impression of the Minor music are "Dark" (Table 1a), "Clearly" (Table 1e) and "Sad" (Table 1f). Next, the correlation matrixes of these data are shown in Table 2. It can be seen that there exist similar data and dissimilar data between Table $2 \mathrm{a}$ and Table 2b. Furthermore, it is discovered that some correlations are moderately from Table 2a (Q1 to Q6 $(\mathrm{r}=0.72), \mathrm{Q} 2$ to $\mathrm{Q} 7(\mathrm{r}=-0.81)$ and Q4 to Q7 $(\mathrm{r}=-0.66))$ and Table 2b (Q1 to Q6 ( $\mathrm{r}=0.58)$ and Q3 to Q7 ( $\mathrm{r}=0.60)$ ); these are not the same. However, other correlations are weak.

Under the above results and discussion, another method is needed to express the characteristics of the Minor music. Therefore, a new method to draw a combination of box-andwhisker plots and univariate scatter plots [2] [9] [11][12] is used.
Table 1: Basic statistics.

(a) Q1 (Bright (0.00)-Dark (1.00))

\begin{tabular}{ccc}
\hline & $\mathrm{G}^{*}$ & $\mathrm{G}^{* *}$ \\
\hline Max. & 0.86 & 0.87 \\
Min. & 0.60 & 0.47 \\
Mean & 0.73 & 0.70 \\
Median & 0.72 & 0.70 \\
SD $^{* * *}$ & 0.10 & 0.11 \\
\hline
\end{tabular}

(b) Q2 (Nervousness (0.00)-Relax (1.00))

\begin{tabular}{ccc}
\hline & G1 & G2 \\
\hline Max. & 0.88 & 0.88 \\
Min. & 0.00 & 0.00 \\
Mean & 0.36 & 0.34 \\
Median & 0.30 & 0.31 \\
SD & 0.30 & 0.20 \\
\hline
\end{tabular}

(c) Q3 (Simple (0.00)-Complex (1.00))

\begin{tabular}{ccc}
\hline & G1 & G2 \\
\hline Max. & 0.89 & 0.89 \\
Min. & 0.53 & 0.24 \\
Mean & 0.73 & 0.67 \\
Median & 0.79 & 0.69 \\
SD & 0.15 & 0.16
\end{tabular}

(d) Q4 (Spirited (0.00) -Quietness (1.00))

\begin{tabular}{ccc}
\hline & G1 & G2 \\
\hline Max. & 0.78 & 0.95 \\
Min. & 0.00 & 0.00 \\
Mean & 0.46 & 0.49 \\
Median & 0.47 & 0.52 \\
SD & 0.23 & 0.23
\end{tabular}

(e) Q5 (Clearly (0.00)-Vaguely (1.00))

\begin{tabular}{ccc}
\hline & G1 & G2 \\
\hline Max. & 0.76 & 0.76 \\
Min. & 0.05 & 0.00 \\
Mean & 0.28 & 0.29 \\
Median & 0.24 & 0.24 \\
SD & 0.23 & 0.19 \\
\hline
\end{tabular}

(f) Q6 (Happy (0.00)-Sad (1.00))

\begin{tabular}{ccc}
\hline & G1 & G2 \\
\hline Max. & 0.84 & 1.00 \\
Min. & 0.56 & 0.38 \\
Mean & 0.69 & 0.74 \\
Median & 0.66 & 0.75 \\
SD & 0.09 & 0.15 \\
\hline
\end{tabular}

(g) Q7 (Like (0.00)-Dislike (1.00))

\begin{tabular}{ccc}
\hline & $\mathrm{G} 1$ & $\mathrm{G} 2$ \\
\hline Max. & 1.00 & 1.00 \\
Min. & 0.06 & 0.06 \\
Mean & 0.56 & 0.47 \\
Median & 0.52 & 0.43 \\
SD & 0.32 & 0.29 \\
\hline${ }^{*}$ : Group 1 $(\mathrm{n}=8)$, \\
** $^{*}$ Group 2 $(\mathrm{n}=22)$, \\
***: Standard deviation. $^{*}$ :
\end{tabular}


Table 2: Correlation matrix.

(a) Group $1(\mathrm{n}=8)$

\begin{tabular}{ccccccc}
\hline & Q1 & Q2 & Q3 & Q4 & Q5 & Q6 \\
\hline Q2 & -0.30 & & & & & \\
Q3 & 0.29 & -0.01 & & & & \\
Q4 & 0.05 & 0.36 & -0.50 & & & \\
Q5 & 0.37 & 0.15 & 0.26 & -0.03 & & \\
Q6 & 0.72 & -0.17 & 0.37 & 0.36 & 0.31 & \\
Q7 & 0.35 & -0.81 & 0.49 & -0.66 & 0.18 & 0.29 \\
\hline
\end{tabular}

(b) Group $2(\mathrm{n}=22)$

\begin{tabular}{ccccccc}
\hline & Q1 & Q2 & Q3 & Q4 & Q5 & Q6 \\
\hline Q2 & -0.36 & & & & & \\
Q3 & -0.10 & 0.03 & & & & \\
Q4 & -0.13 & 0.30 & -0.17 & & & \\
Q5 & -0.01 & 0.22 & -0.06 & 0.21 & & \\
Q6 & 0.58 & -0.09 & -0.19 & -0.12 & 0.12 & \\
Q7 & 0.23 & -0.51 & 0.60 & -0.21 & -0.09 & -0.03 \\
\hline
\end{tabular}

\section{Combination of Box-and-Whisker Plots and Uni- variate Scatter Plots}

In order to clarify relationships or meanings of Q1 to Q7 for the Minor music, the combination of box-and-whisker plots and univariate scatter plots [10] [11] is shown as Fig. 4. And to examine and compare the box-and-whisker plots and univariate scatter plots, they are overlaid and visualized as Fig. 5. From Fig. 4 and Fig. 5, it can be seen that the participants of both groups received similar impressions from the Minor music. And it turns out that there are specific trends in Q1, Q5, and Q6. That is, distribution trends of Q1 and Q6 are higher values, (i.e., "Dark" and "Sad"), and that of Q5 is lower values, (i.e., "Clearly"). On the other hand, it can be seen that distribution trends of Q2 are lower values and that of Q3 is higher values. However, their box length is longer than Q1, Q5, and Q6. Therefore, it is considered that distributions of Q2 and Q3 are not characteristic.

From the above procedure, it is considered that the characteristics of the impression of the Minor music is clarified. And it is also considered that these facts are evidence of section 4.1 .

\subsection{Hierarchical Clustering Analysis by Ward Method} and Non-Hierarchical Clustering analysis by k-means Figure 6 shows the cluster dendrogram from Q1 to Q7 for the Minor music. And it is considered that these are divided into three clusters from Fig. 4 and Fig. 5. More, these two figures in Fig. 6 can be regarded as the same. From Fig. 6 , therefore, it can also be seen that the participants of both groups received similar impressions from the Minor music, and the relationships and meanings of Q1 to Q7, (i.e., the basis of their answers) are also similar. Furthermore, the number of clusters is defined as three, non-hierarchical clustering analysis by k-means are also carried out. This result is the same as in Fig. 6. Furthermore, the clustering from Q1 to Q7 and the meanings of these are summarized in Table 3 [12]. According to Table 3, it can be possible to ex-

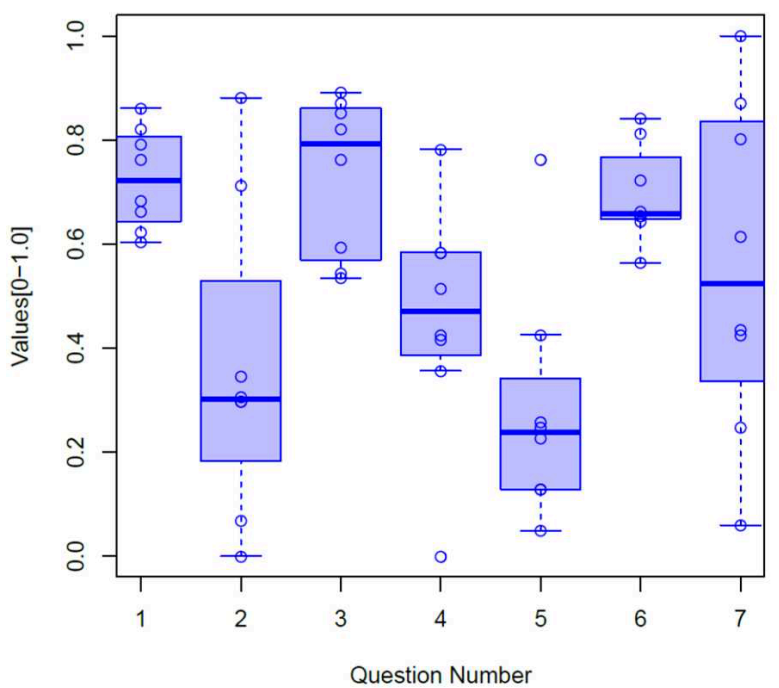

(a) Group $1(n=8)$

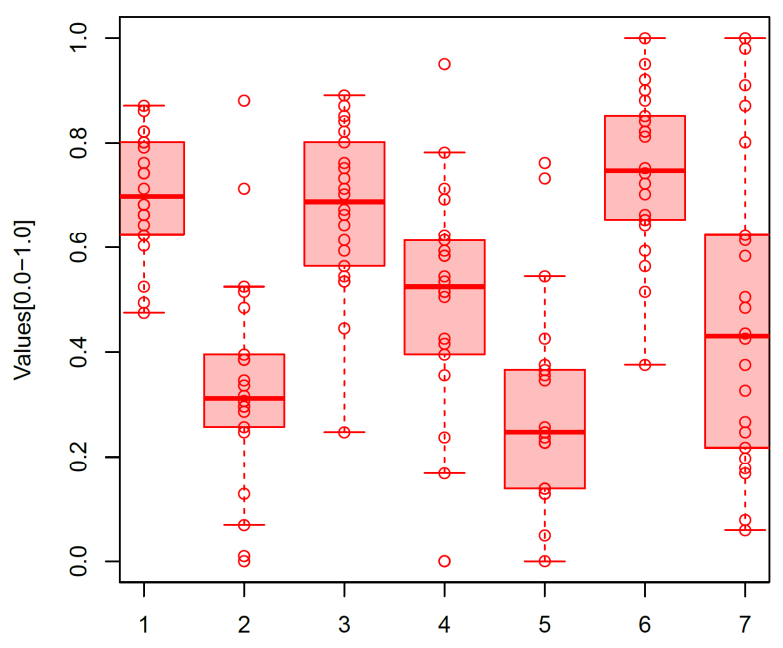

(b) Group $2(\mathrm{n}=22)$

Figure 4: Combination of univariate scatter plots and boxand-whisker plots (1).

press the relationship and meaning of questions as a specific phrase. Moreover, it has been confirmed that Q1 ("BrightDark") and Q6 ("Happy-Sad") belong to the same cluster. This fact has also been confirmed in our previous studies (expression of different impressions by different types of music) [2] [12]. Hence, Q1 and Q6 are considered to be the basic elements that determine the impression of music by the experiment participants as same as our previous studies [2] [12].

However, these results and discussion are limited to the case of an impression of one Minor music. Therefore, applying SWM for another music (such as another Minor music, major music, and so on) or another field is expected and these are very important. Thus, conducting more investigations is also necessary.

\section{Conclusion}

Under these results and discussion, it concludes as follows: the participants in the two groups received similar impres- 


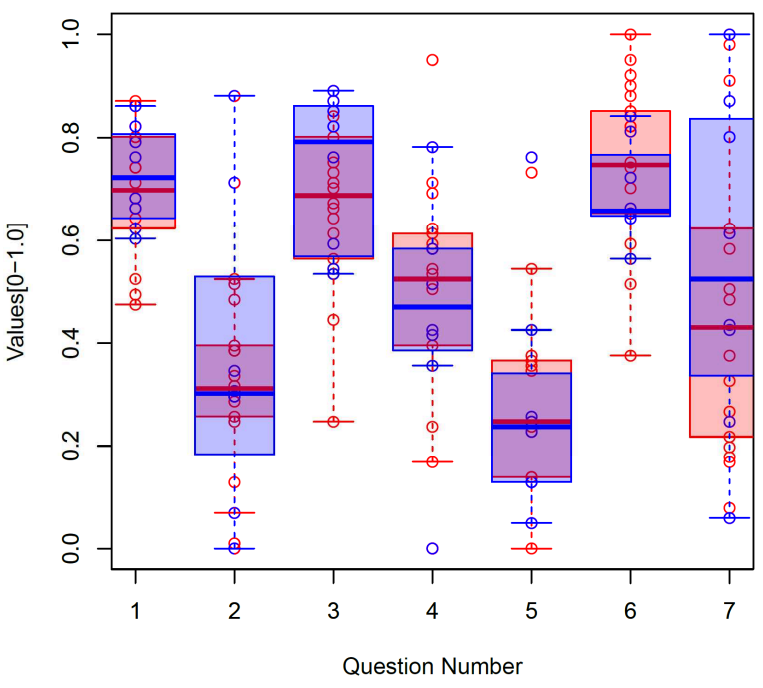

Figure 5: Combination of univariate scatter plots and boxand-whisker plots (2) (overlaid Fig. 4a and Fig. 4b).

Table 3: Clustering by k-means from Q1 to Q7 and their meanings.

\begin{tabular}{|c|c|}
\hline $\begin{array}{l}\text { Cluster 1: } \\
\text { Meaning: }\end{array}$ & $\begin{array}{l}\text { Q7 ("Like-Dislike") } \\
\text { A preference of participants }\end{array}$ \\
\hline Cluster 2: & $\begin{array}{l}\text { Q1 (“Bright-Dark"), Q6 ("Happy-Sad"), } \\
\text { Q3 (“Simple-Complex") }\end{array}$ \\
\hline Meaning: & $\begin{array}{l}\text { Impressions of intuitive and easy to } \\
\text { understand }\end{array}$ \\
\hline Cluster 3: & $\begin{array}{l}\text { Q2 (“Nervousness-Relax”), } \\
\text { Q5 (“Clearly-Vaguely"), } \\
\text { Q4 (“Spirited-Quietness") }\end{array}$ \\
\hline Meaning: & $\begin{array}{l}\text { Impressions that are difficult to understand } \\
\text { (such as emotional, musical, etc.) }\end{array}$ \\
\hline
\end{tabular}

sions from the Minor music, and they answer the VAS questionnaire in the same way. And the bases of their answers are also similar. However, to obtain reliable conclusions, applying SWM in future study such as another field and conducting more investigation are very important. More, it is also very important to compare and examine this proposed method and another method by small samples.

Future works are as follows: (1) applying SWM in another music or field; (2) comparison of SWM and other methods by small samples; (3) measurement with a larger number of participants and (4) clustering of participants.

\section{Acknowledgment}

This work is partially supported by JSPS Grants-in-Aid for Scientific Research, No.16K01890.

\section{References}

[1] S. Watanabe, R. Takaue, F. Yao, Y. Matsumoto, H. Tsukamoto, N. Shirahama, N. Nakaya and Y. Mori, "Effects of 1/f Fluctuation Music Listening on Autonomic Ner-

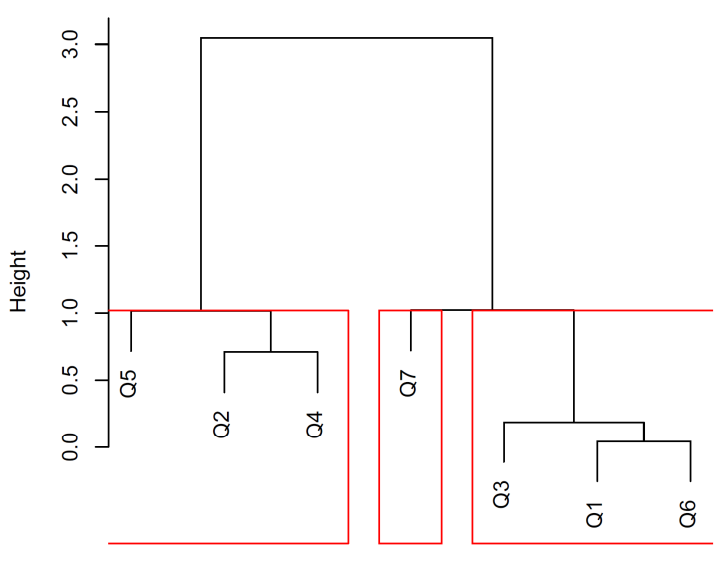

Question Number hclust (*, "ward.D2")

(a) Group $1(\mathrm{n}=8)$

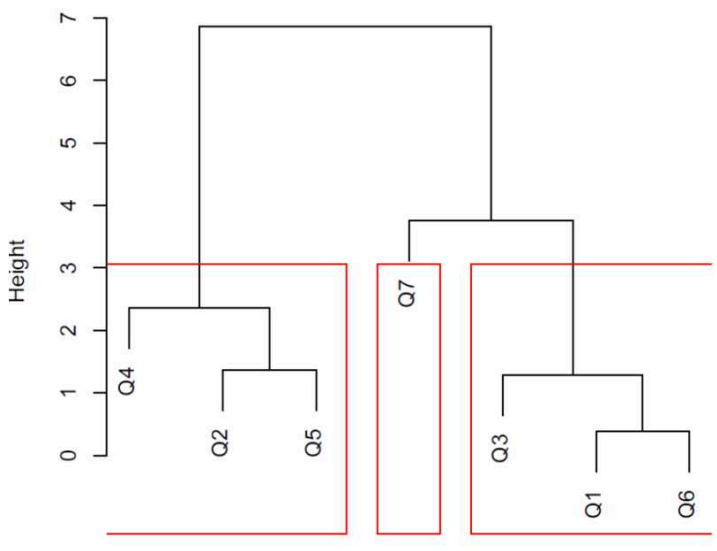

Question Number hclust (*, "ward.D2")

(b) Group $2(\mathrm{n}=22)$

Figure 6: Cluster dendrogram.

vous System Activity", Journal of the Institute of Industrial Applications Engineers, Vol.6, No.2, pp.86-91, 2018. DOI: 10.12792/JIIAE.6.86

[2] S. Watanabe, N. Shirahama, N. Nakaya, Y. Matsumoto and Y. Mori, "An Expression of the Impression of Three Pieces of Sounds Based on Visual Analog Scale Analysis", International Journal of Biomedical Soft Computing and Human Sciences, Vol.24, No.2, pp.75-82, 2019.

[3] R. A. Likert, "Technique for the Measurement of Attitudes", Archives of Psychology (New York), 1932.

[4] D. Peabody, "Two components in bipolar scales: Direction and extremeness", Psychological Review, Vol.69, No.2, pp.65-73, 1962. DOI: 10.1037/h0039737

[5] H. S. Upshaw, "Own attitude as an anchor in equal-appearing intervals", The Journal of Abnormal and Social Psychology, Vol.64, No.2, pp.85-96, 1962. DOI: 10.1037/h0048600

[6] R. A. Cummins, "The second approximation to an international standard for life satisfaction", Social Indica- 
tors Research, Vol.43, No.3, pp.307-334, 1998. DOI: 10.1023/A:1006831107052

[7] S. J. Heine, D. R. Lehman, K. Peng and J. Greenholtz, "What's wrong with cross-cultural comparisons of subjective Likert scales?: The reference-group effect", Journal of personality and social psychology, Vol.82, No.6, pp.903-918, 2002. DOI: 10.1037/0022-3514.82.6.903

[8] S. Watanabe, N. Shirahama, H. Tsukamoto, Y. Matsumoto, M. Nakagawa, K. Miyamoto, N. Nakaya, M. Tomita and Y. Mori, "Trend of the Subjective Evaluation based on Visual Analog Scale and Likert Scale", ICIC Express Letters, Part B: Applications (ICIC-ELB), Vol.7, No.1, pp.37-42, 2016.

[9] S. Watanabe, N. Shirahama, Y. Matsumoto, H. Tsukamoto, M. Nakagawa, K. Miyamoto, N. Nakaya, M. Tomita and Y. Mori, "Distribution Trend of the Information Skills for Students Based on Visual Analog Scale and Likert Scale", International Journal of Biomedical Soft Computing and Human Sciences, Vol.20, No.2, pp.1-6, 2016. DOI: 10.24466/ijbschs.20.2 1

[10] T. L. Weissgerber, N. M. Milic, S. J. Winham and V. D. Garovic, "Beyond Bar and Line Graphs: Time for a New Data Presentation Paradigm", PLOS Biology, Vol.13, No.4: e1002128, 2015. DOI: 10.1371/journal.pbio.1002128

[11] N. Shirahama, S. Watanabe, K. Moriya, K. Koshi and K. Matsumoto, "A New Method of Subjective Evaluation Using Visual Analog Scale for Small Sample Data Analysis", Journal of Information Processing, Vol.29, pp.424-433, 2021. DOI: $10.2197 /$ ipsjjip.29.424

[12] S. Watanabe, N. Shirahama, Y. Matsumoto, H. Tsukamoto, N. Nakaya and Y. Mori "Subjective Evaluation for the Impression of Music Based on Visual Analog Scale and Cluster Analysis", Journal of Biomedical Fuzzy Systems Association, 19(2), 53-65, 2017 (In Japanese).

[13] S. Watanabe, T. Tsuruta, N. Shirahama, N. Nakaya, Y. Matsumoto, H. Tsukamoto and Y. Mori, "Expression of Subjective Evaluation for the Participation Attitude to the Internet of Male College Students Based on Visual Analog Scale", Journal of the Institute of Industrial Applications Engineers, Vol.8, No.1, pp.16-23, 2020.

[14] E. Hoshino, "Impression and Recognition of Songs: Relationships between Lyrics and Melody in a Song", IPSJ Special Interest Group on Music and Computer, 2002-MUS-45, 109-114, 2002 (in Japanese).

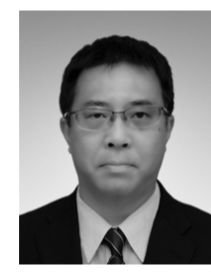

Satoshi Watanabe (Member) received his $\mathrm{Ph} . \mathrm{D}$. degree in information system from University of East Asia, Shimonoseki, in 2008. He is currently an associate professor at School of Health Sciences at Odawara, International University of Health and Welfare. His current research interests are informatics, human science and educational technology. $\mathrm{He}$ is a member of IIAE, BMFSA, IPSJ, JSET and so on.

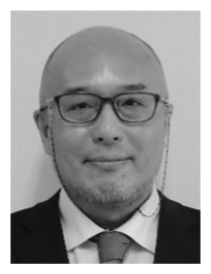

Naruki Shirahama (Member) received his $\mathrm{Ph} . \mathrm{D}$. degree in electrical engineering from Kyushu Institute of Technology in 2000. He has been working as a professor at National Institute of Technology (KOSEN), Kitakyushu College. His current research interest is the application of the subjective observation model. $\mathrm{He}$ is a member of IIAE, BMFSA, IPSJ, IEEE, J-SOFT, JSWE, JSKE and JSAI.

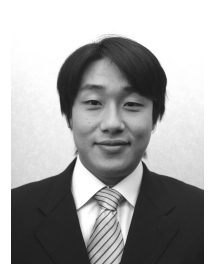

Naofumi Nakaya(Member) received his Ph.D. degree from Nihon University in 2015. $\mathrm{He}$ is currently an assistant professor at Tsukuba International University. $\mathrm{He}$ is a member of IIAE and BMFSA.

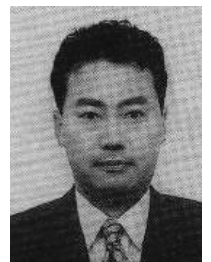

Yuji Matsumoto (Non-member) received his Ph.D. degree from Osaka University. $\mathrm{He}$ is curently a professor at Junior College Division, Kindai University. He is a member of BMFSA. 